\title{
Immobilization of Synthetic Bilayer Membranes as Multilayered Polymer Films ${ }^{\dagger}$
}

\author{
Masatsugu SHImomURA and Toyoki KUnITAKE* \\ Department of Organic Synthesis, Faculty of Engineering, \\ Kyushu University, Fukuoka-shi 812, Japan \\ (Received October 25, 1983)
}

\begin{abstract}
KEY WORDS Bilayer Membrane / Immobilization / Polymer Film / Dialkylammonium Salt /
\end{abstract}

The synthetic bilayer membrane is prepared from a large variety of amphiphiles which include single-chain, double-chain, triplechain, and polymeric compounds, and possess physicochemical characteristics common to the bilayer membrane of biolipids. ${ }^{1}$ The combination of unique physicochemical properties and the structural versatility makes the synthetic bilayer membrane promising as novel functional material. However, functional applications have been limited since synthetic bilayers are usually obtained as aqueous dispersions. This paper shows that by proper combinations with polymers, it is possible to produce immobilized bilayers which though not soluble in water, still possess the bilayer characteristics common to those of an aqueous dispersion.

We showed recently that transparent films remain on glass by casting aqueous bilayers. ${ }^{2,3}$ These films, however, tend to dissolve on prolonged contact with water, and dried films are often devoid of dynamic physicochemical properties characterizing aqueous bilayers. Similar situations more or less arise for a bilayer aggregate loaded in porous polymer membranes,${ }^{4}$ although it is well protected in the nonpermeable poly(vinyl chloride) matrix. ${ }^{5}$

Bilayer membranes, being stable aggregates of very large molecular weight, may be protected from disintegration in water by covering them with thin layers of water-insoluble, permeable films. Cellulose acetate (CA) is a polymer of choice since only water readily permeates the CA membrane. Aqueous bilayers of dialkylammonium salts ${ }^{6}$ can be cast on a CA film, whereas CA in acetone cannot, owing to the solubility of the bilayer components in acetone. To avoid dissolution, acetoneinsoluble polymers were used as binders. Poly(vinyl alcohol) (PVA) was suitable for this purpose, since the bilayer structure is retained in this matrix. ${ }^{7}$

Three-layered films (a PVA-bilayer composite layer sandwiched between two layers of CA) were prepared by two different procedures. In the first procedure, cast films of the PVA-bilayer composite were dipped in an acetone solution of CA and dried at room temperature under saturated acetone vapor. The film became opaque, when drying was too quick. The thickness of the CA layer was not easy to control by this procedure.

† Contribution No. 710 from Department of Organic Synthesis.

* Address correspondence to this author. 


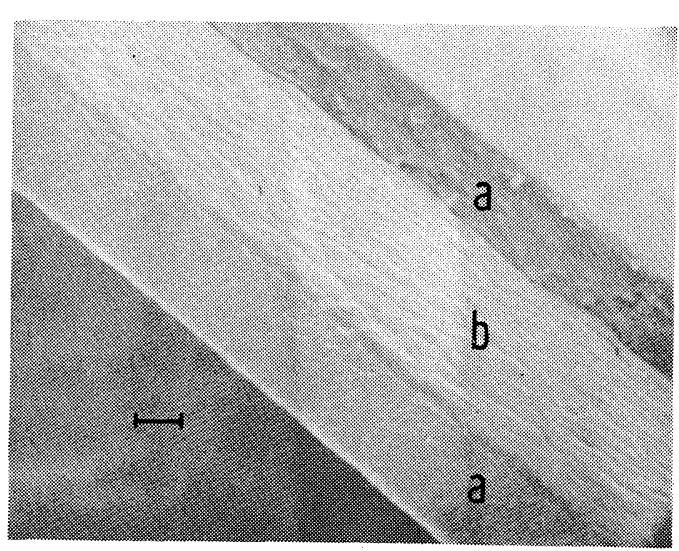

Figure 1. Scanning electron micrograph of a crosssection of a three-layered film. bar, $10 \mu \mathrm{m}$; a, CA layer; b, PVA-bilayer composite layer. The vertical shades are artifacts.

In the other procedure, an aqueous PVAbilayer composite was cast on a CA film; this composite was then topped with a casting of CA. An aqueous solution $(1 \mathrm{ml})$ of $50 \mathrm{mg}$ of bilayer components (the mole ratio of $2 \mathrm{C}_{18} \mathrm{~N}^{+} 2 \mathrm{C}_{1}$ and $\mathrm{C}_{8} \mathrm{AzoC}_{10} \mathrm{~N}^{+}$was $\left.10: 1\right)$ and aqueous PVA $(200 \mathrm{mg}$ in $4 \mathrm{ml})$ were gently mixed, placed on a pre-cast film of cellulose acetate (300 $\mathrm{mg}$ from $6 \mathrm{ml}$ acetone), and dried in vacuo. Cellulose acetate $(300 \mathrm{mg})$ in $6 \mathrm{ml}$ acetone was placed on the double-layered film and cast slowly under saturated acetone vapor.

Figure 1 is a scanning electron micrograph of a cross-sectional view of the film prepared by the second procedure from a mixed bilayer of $2 \mathrm{C}_{18} \mathrm{~N}^{+} 2 \mathrm{C}_{1}$ and $\mathrm{C}_{8} \mathrm{Az \rho C} \mathrm{C}_{10} \mathrm{~N}^{+} .8$ The threelayer structure can be clearly seen. The bilayercomposite layer (b, ca. $30 \mu \mathrm{m})$ is sandwiched between two CA layers (a, 10 and $20 \mu \mathrm{m}$ ). The possible release of the bilayer component from between the two CA layers was tested by measuring the absorbance of film-bound $\mathrm{C}_{8} \mathrm{AzoC}_{10} \mathrm{~N}^{+}$. Only $5 \%$ of the bilayer component was released following incubation in water for $1 \mathrm{~h}$ at $60^{\circ} \mathrm{C}$. This release could probably be more effectively repressed by an improved casting procedure.

$$
\begin{aligned}
& \mathrm{CH}_{3}\left(\mathrm{CH}_{2}\right) 17^{-}{ }^{\mathrm{CH}_{3}}\left(\mathrm{CH}_{2}\right) 17+\mathrm{CH}_{3} \mathrm{Br}^{-}
\end{aligned}
$$

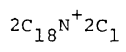

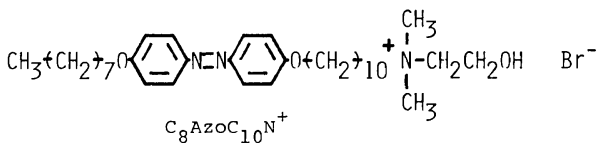

The dynamic bilayer characteristics could be easily examined on the basis of the phase separation behavior. The phase separation behavior of azobenzene amphiphiles in a bilayer matrix has been studied extensively, along with its application to functionalized membranes. ${ }^{9,10}$ Blue shifts of the azobenzene chromophore are observed when amphiphile $\mathrm{C}_{8} \mathrm{AzoC}_{10} \mathrm{~N}^{+}$forms clusters in the matrix.

Figure 2 shows spectral changes in a sandwiched film containing a bilayer mixture of $2 \mathrm{C}_{18} \mathrm{~N}^{+} 2 \mathrm{C}_{1}$ and $\mathrm{C}_{8} \mathrm{AzoC}_{10} \mathrm{~N}^{+}$in the $10: 1$ molar ratio. The three-layer film prepared on a quartz plate was immersed in water in a quartz cell. At $10^{\circ} \mathrm{C}, \lambda_{\max }$ was located at $305 \mathrm{~nm}$, indicating the presence of azobenzene amphiphile clusters. ${ }^{9}$ On raising the temperature, the peak at $305 \mathrm{~nm}$ diminished and a new peak appeared at $355 \mathrm{~nm}$ (monomeric species). These changes are schematically shown in the figure. Figure 3 illustrates a differential scanning calorimetry (DSC) curve and the temperature dependence of the $360-\mathrm{nm}$ absorbance of the sandwiched film immersed in water. Polymer films $(10-20 \mathrm{mg})$ were cut into pieces and placed in Ag sample pans with and without water $(50 \mu \mathrm{l})$. The experimental details are given elsewhere. ${ }^{11}$ The heating curve in Figure $3 \mathrm{~b}$ corresponds to the spectral change in Figure 2 and the increase in monomeric absorbance levels off at $45^{\circ} \mathrm{C}$ which is close to $T_{\mathrm{c}}$ of $2 \mathrm{C}_{18} \mathrm{~N}^{+} 2 \mathrm{C}_{1}$ (peak top in Figure $3 \mathrm{a}, 44^{\circ} \mathrm{C}$ ). The spectrum does not revert completely in the cooling process.

When measurement was conducted without immersion in water (Figure 4), $T_{\mathrm{c}}$ moved to $68^{\circ} \mathrm{C}$, and the monomer spectrum increased 

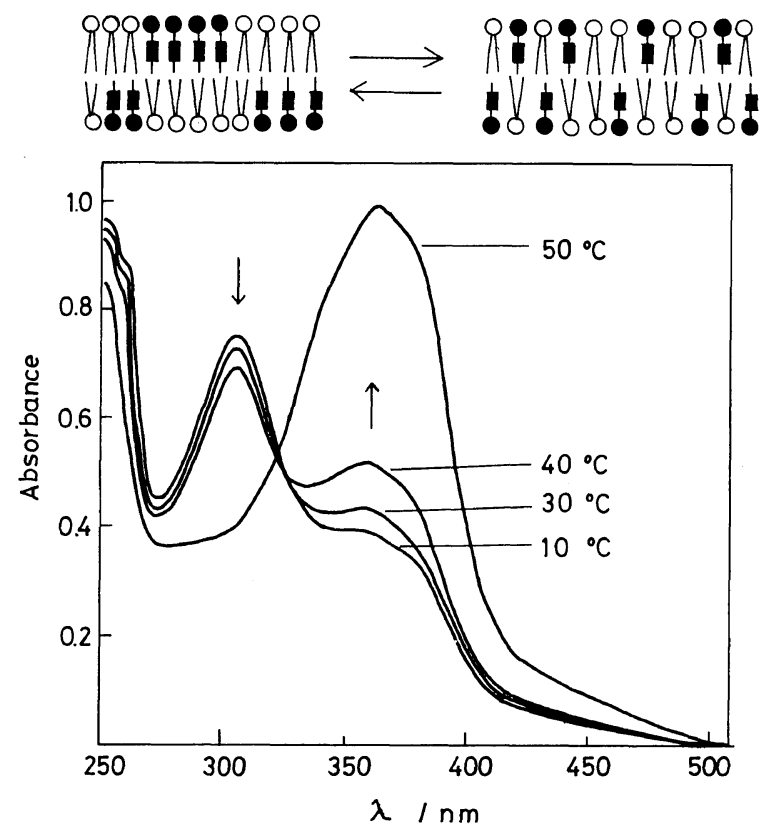

Figure 2. Absorption spectra of a sandwiched film immersed in water. Film prepared in a manner similar to that of Figure 1.
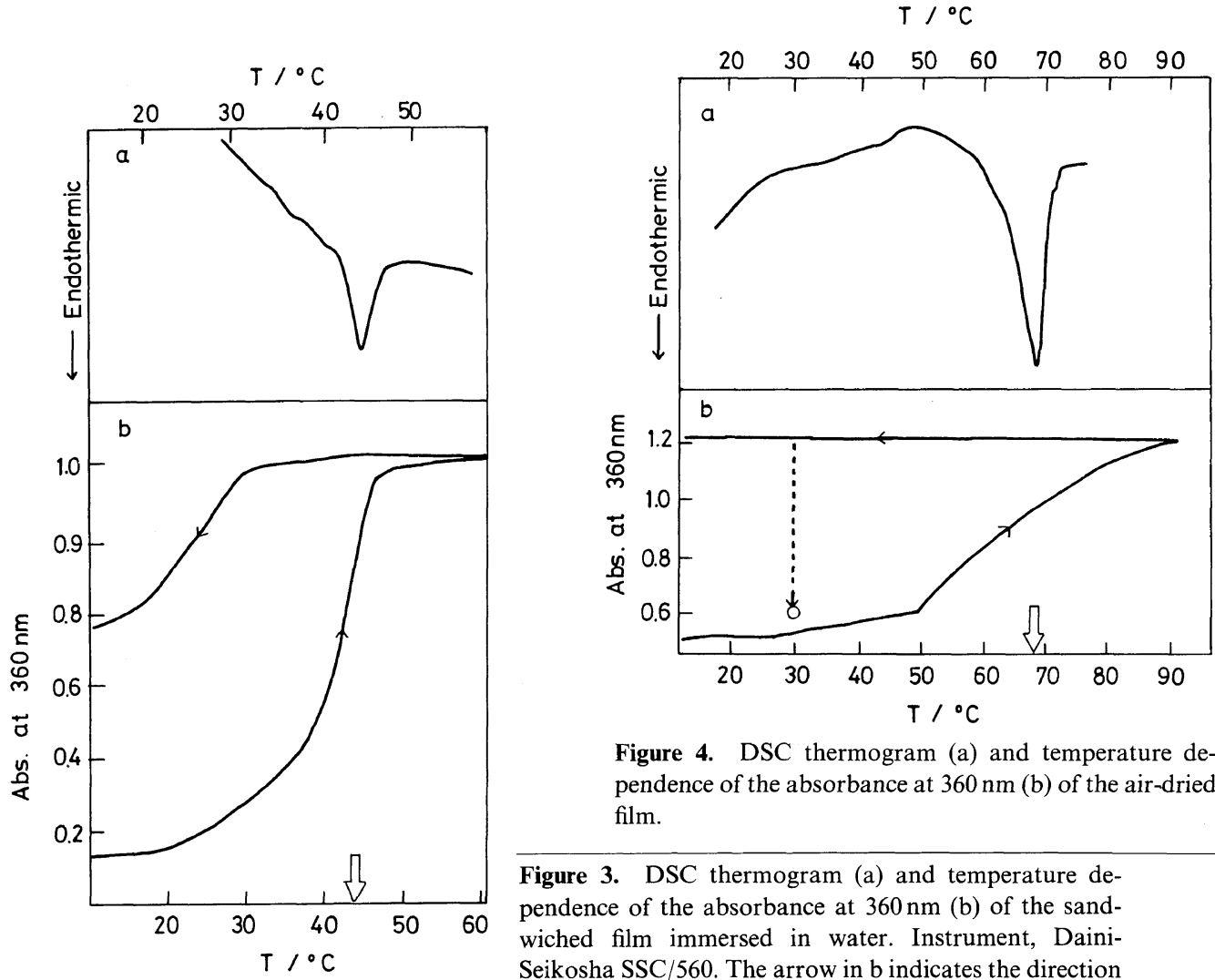

Figure 4. DSC thermogram (a) and temperature dependence of the absorbance at $360 \mathrm{~nm}$ (b) of the air-dried film.

Figure 3. DSC thermogram (a) and temperature dependence of the absorbance at $360 \mathrm{~nm}$ (b) of the sandwiched film immersed in water. Instrument, DainiSeikosha SSC $/ 560$. The arrow in $\mathrm{b}$ indicates the direction of temperature change $\left(2^{\circ} \mathrm{C} \mathrm{min}^{-1}\right)$. 
gradually from at $\mathrm{ca} .50$ to $90^{\circ} \mathrm{C}$. The spectrum did not change with temperature in the cooling process. The homogeneous mixing attained at high temperatures remained intact in the dry film at all temperatures. However, the cluster species were capable of being regenerated in $10-20 \mathrm{~min}$ on immersing the film in water at temperatures below $30^{\circ} \mathrm{C}$, as indicated by the dotted line.

It was established from these results that the sandwiched film described in this paper maintain the dynamic bilayer characteristics on contact with water. This immobilization procedure will be useful in the development of bilayer-based functional materials.

Acknowledgement. We are grateful to Prof. M. Takayanagi for the use of a scanning electron microscope. This work was supported in part by Special Coordination Funds for Promoting Science and Technology (Science and Technology Agency of Japan).

\section{REFERENCES AND NOTES}

1. T. Kunitake and Y. Okahata, J. Am. Chem. Soc., 99, 3860 (1977) and the subsequent publications.

2. N. Nakashima, R. Ando, and T. Kunitake, Chem. Lett., 1577 (1983).

3. M. Shimomura, R. Ando, and T. Kunitake, Ber. Bunsenges. Phys. Chem., 87, 1134 (1983).

4. Y. Okahata, S. Hachiya, and G. Nakamura, Chem. Lett., 1719 (1982).

5. T. Kajiyama, A. Kumano, M. Takayanagi, Y. Okahata, and T. Kunitake, Chem. Lett., 645 (1979).

6. T. Kunitake, Y. Okahata, K. Tamaki, M. Takayanagi, and F. Kumamaru, Chem. Lett., 387 (1977).

7. S. Hayashida, H. Sato, and S. Sugawara, Chem. Lett., 625 (1983).

8. A piece of the three-layer film was immersed in liquid nitrogen and fractured. Gold was sputtered on the fractured surface and observed by Hitachi S-450 scanning electron microscope.

9. M. Shimomura and T. Kunitake, Chem. Lett., 1001 (1981).

10. M. Shimomura and T. Kunitake, J. Am. Chem. Soc., 104, 1757 (1982).

11. Y. Okahata, R. Ando, and T. Kunitake, Ber. Bunsenges. Phys. Chem., 85, 789 (1981). 